\title{
Two-Layer Dynamic Recycling Model (2L-DRM): Learning from Moisture Tracking Models of Different Complexity
}

\author{
F. DOMINGUEZ \\ Department of Atmospheric Sciences, University of Illinois at Urbana-Champaign, Urbana, Illinois \\ H. HU \\ Atmospheric Sciences and Global Change Division, Pacific Northwest National Laboratory, Richland, Washington \\ J. A. MARTineZ \\ Escuela Ambiental, Universidad de Antioquia, Medellin, Colombia
}

(Manuscript received 7 May 2019, in final form 23 October 2019)

\begin{abstract}
Atmospheric moisture tracking models are used to identify and quantify sources and sinks of water in the atmospheric branch of the hydrologic cycle. These models are primarily used to investigate the origin of moisture resulting in precipitation for particular regions around the globe. Moisture tracking models vary widely in their level of complexity, depending on the number of physical processes represented. Complex models are comprehensive in their physical representation, but computationally much more expensive than simple models, which only focus on specific physical processes and use simplifying assumptions. We present the mathematical derivation of the new two-layer dynamical recycling model (2L-DRM), a simple analytical moisture tracking model that relaxes the vertically integrated formulation of the original one-layer DRM. By comparing the simple DRM to a very complex moisture tracking model that uses water vapor tracers embedded within the Weather Research and Forecasting regional climate model (WRF-WVT) for the North American monsoon region, we pinpoint the absence of vertical wind shear as the main deficiency in the simple DRM. When comparing both simple models (DRM and 2L-DRM) to the WRF-WVT (which we treat as "truth"), the 2L-DRM better captures the spatial extent, the net amount, and the temporal variability of precipitation that originates from oceanic and local terrestrial sources. The 2L-DRM is well suited to study the large-scale climatological sources of moisture, and for these applications, performs on par with the much more complex and computationally demanding WRF-WVT model.
\end{abstract}

\section{Introduction}

The models used for numerical tracking of moisture range in complexity from simple analytical "box" models to numerical tracers embedded within regional or global climate models (Gimeno et al. 2012). The development of moisture tracking schemes dates back to the 1970s and has rapidly evolved in the last decade. Figure 1 shows the different types of models organized in terms of complexity in their construction, defined here as the physical processes included in the tracking algorithm to represent change in atmospheric moisture. These processes include time rate of change of moisture storage, advection in the horizontal and vertical direction

Corresponding author: F. Dominguez, francina@illinois.edu
(1D, 2D, 3D), diffusion, divergence of turbulent moisture flux, and change of phase. Note that our definition of complexity is not necessarily linked to computational cost, physical realism, or additional information provided by the model such as age of water. The first category includes "analytical" models that provide simple budget equations to quantify sources and sinks of precipitation. The simplest model is the steady-state, one-dimensional model of Budyko (1974). The model we derive in this manuscript is an analytical model with two 2D layers. The second category includes "offline" models that rely on diagnostics based on the output of atmospheric models or reanalyses and provide estimates of sources and sinks without the need for analytical solutions. While "offline Eulerian" models are usually 2D [except van der Ent et al. (2014), which has two 2D layers], 


\begin{tabular}{|c|c|c|}
\hline \multirow[b]{2}{*}{$\frac{\sqrt{0}}{\frac{.0}{+}}$} & $\stackrel{\square}{ }$ & $\begin{array}{l}\text { Budyko (1974) } \\
\text { Drozdov and Grigor'era (1965) } \\
\text { Lettau et al. (1979) } \\
\text { Savenije (1995) } \\
\text { Schaefli et al. (2012) }\end{array}$ \\
\hline & 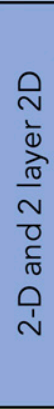 & $\begin{array}{l}\text { Brubaker et al. (1993) } \\
\text { Eltahir and Bras (1996) } \\
\text { Burde and Zangvil (2001) } \\
\text { Fitzmaurice (2007) } \\
\text { Burde et al. (2006) } \\
\text { Dominguez et al. (2006) } \\
\text { Martinez and Dominguez (2014) } \\
\text { van der Ent and Savenije (2011) } \\
\text { Dominguez et al (this study) } \\
\end{array}$ \\
\hline \multirow[b]{2}{*}{ 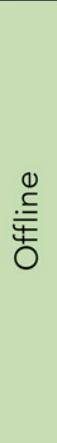 } & $\frac{\frac{c}{\frac{C}{2}}}{\frac{2}{d}}$ & $\begin{array}{l}\text { Goessling and Reick (2011) } \\
\text { van der Ent et al. (2010) } \\
\text { Yoshimura et al. (2004) } \\
\text { van der Ent et al. (2014) } \\
\end{array}$ \\
\hline & 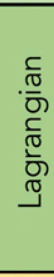 & $\begin{array}{l}\text { Dirmeyer and Brubaker (2007) } \\
\text { Stohl and James (2004) } \\
\text { Perez Munuzuri et al. (2018) } \\
\text { de Leeuw et al. (2017) } \\
\text { Gustafsson et al. (2010) } \\
\text { Sodemann et al. (2008) } \\
\end{array}$ \\
\hline \multirow{2}{*}{ 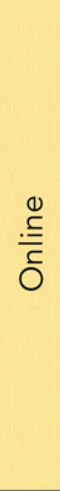 } & $\begin{array}{l}\bar{\pi} \\
\frac{\Omega}{0} \\
\text { 은 }\end{array}$ & $\begin{array}{l}\text { Koster et al. (1986) } \\
\text { Joussaume et al. (1984) } \\
\text { Numaguti (1999) } \\
\text { Bosilovich and Schubert (2001) } \\
\text { Goessling and Reick (2013) }\end{array}$ \\
\hline & 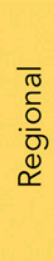 & $\begin{array}{l}\text { Sodemann et al. (2009) } \\
\text { Winschall et al. (2014) } \\
\text { Knoche and Kunstmann (2013) } \\
\text { Arnault et al. (2016) } \\
\text { Miguez-Macho et al. (2013) } \\
\text { Insua-Costa and Miguez-Macho (2018) }\end{array}$ \\
\hline
\end{tabular}

FIG. 1. List of models to track sources and sinks of precipitation organized in terms of model complexity defined here as the physical processes included in the tracking algorithm to represent change in atmospheric moisture. The models are divided into three categories: analytical (blue), offline (green), and online models (yellow).

"offline Lagrangian" models are three-dimensional, and hence must account for the vertical movement of the parcels. The last category is "online models," which rely on prognostic water tracers embedded within global or regional climate models. These models include some representation of convection, microphysics, and/or turbulence (processes that are necessarily simplified in the offline models). As an example, the model in
Insua-Costa and Miguez-Macho (2018) includes sixspecies microphysics, has the ability to resolve convection, and can trace water originating from a 3D volume. It is important to highlight that we are only listing models that specifically track water; we do not include the many models that are used for water isotopes, with the exception of the original Joussaume et al. (1984) model. Although we have strived to include all available models we realize that the list is likely nonexhaustive. This range of model complexity presents an opportunity for process understanding. The model results will change when key sources of complexity are added or subtracted, and our understanding increases when we can identify the interrelationships between the models of different levels of complexity (Held 2005).

In the context of moisture tracking, the vast majority of studies have used only one model and applied it globally or to certain geographic locations; few studies have critically assessed the strengths and weaknesses of individual models through the exercise of hierarchical model intercomparison. Three notable exceptions are van der Ent et al. (2013, hereafter VE2013), Goessling and Reick (2013), and Dominguez et al. (2016). While they analyze different models, periods of time, and geographical regions, these three studies highlight two critical points:

1) In regions and/or seasons of strong wind shear, the assumptions of complete vertical mixing are not met and 2D models tend to incorrectly estimate moisture source direction. This tends to be the greatest source of error for simple 2D models. However, adding one layer to the simple 2D schemes significantly alleviates the problem, as in WAM-2layers described in van der Ent et al. (2014).

2) The vertical height from where water vapor contributes to precipitation is not always proportional to the level's mixing ratio. In general, water vapor from lower atmospheric levels contributes significantly more to precipitation than upper-level moisture. This is particularly true in terms of convective precipitation (Bosilovich 2002). This process has been called "fast recycling" (Lettau et al. 1979) and leads to an underestimation of terrestrial sources of moisture by simple models when compared to water vapor tracers in climate models (Goessling and Reick 2013).

The goal of this manuscript is to present the mathematical derivation of the new two-layer dynamical recycling model (2L-DRM) in which we relax the one-layer assumption of the simple DRM analytical model. We will compare the new 2L-DRM with water vapor tracers embedded in the Weather Research and Forecasting Model (WRF-WVT) (Insua-Costa and Miguez-Macho 2018). 
While the new 2L-DRM model addresses the DRM's problems in regions/seasons of strong shear, it does not address the vertical mixing problem. The motivation for our current model development was the comparison between the WRF-WVT simulations and DRM simulations described in Dominguez et al. (2016). In that study, moisture from four different regions that contribute to North American monsoon (NAM) precipitation was tagged for 10 consecutive monsoon seasons (2004-13) using WRF-WVT. When compared to the DRM analysis for the same region (using the WRF-WVT as input data for DRM), Dominguez et al. (2016) found that the largest deficiency in the DRM model, when used to analyze moisture sources within the NAM region, is related to the DRM's inability to account for the wind shear that prevents this single-layer model from correctly tracking moisture sources. The NAM region is particularly interesting, because it is a region of strong vertical wind shear, where moisture sources have been extensively studied in the past (Bosilovich et al. 2003; Dominguez et al. 2008; Hu and Dominguez 2015). This work follows a very similar strategy as VE2013 in the sense that the regional model with tracers (in this case WRF-WVT) is taken to be the "truth" and the simple models are critically analyzed by comparing them to the complex model. It differs from VE2013 in that we are working with different models and we analyze a 10-yr climatology of the NAM, as opposed to a specific month. In this way we are able to assess the simple model in terms of climatologies of moisture transport.

\section{Methods}

Within a regional or global atmospheric model, the prognostic equation for total moisture in the atmosphere is expressed as

$$
\begin{aligned}
\frac{\partial q_{n}}{\partial t}= & -\mathbf{v} \cdot \nabla q_{n}+\nu_{q} \cdot \nabla^{2} q_{n}+\left(\frac{\partial q_{n}}{\partial t}\right)_{\mathrm{PBL}} \\
& +\left(\frac{\partial q_{n}}{\partial t}\right)_{\text {microphysics }}+\left(\frac{\partial q_{n}}{\partial t}\right)_{\text {convection }}, \\
\int_{p_{0}}^{0}\left(\frac{\partial q_{n}}{\partial t}=\right. & \left.-\mathbf{v} \cdot \nabla q_{n}+s\right),
\end{aligned}
$$

where $q_{n}$ is the total moisture by each of the $n$ species that we are considering (which could be water vapor, cloud water, rainwater, snow, ice, and graupel). The terms on the right correspond to advection, molecular diffusion, changes in moisture content due to parameterized turbulent transport in the planetary boundary layer (PBL), microphysics, and convection. The three terms on the right can be thought of as source-sink terms related to phase changes, redistribution of moisture by convection, and turbulent fluxes. The most complex moisture tracking models would take into account all of the terms in Eq. (1) at high spatiotemporal resolution. Different assumptions can lead to simplified forms of the equation, and the discussion that follows will discuss the details of the three models used in this study: the DRM, the new two-layer DRM (2L-DRM), and WRF-WVT. Figure 2 schematically shows the three different models, going from simplest (DRM) to most complex (WRF-WVT).

\section{a. Dynamic recycling model}

If we focus only on water vapor, neglect molecular diffusion, treat the atmosphere as one slab (Fig. 2a), and integrate the simplified form of Eq. (1) between the surface and the top of the atmosphere, the conservation of mass can be written as

$$
\frac{\partial(w)}{\partial t}+\frac{\partial(w u)}{\partial x}+\frac{\partial(w v)}{\partial y}=s_{o}-s_{i}=E-P,
$$

where $w=\int_{0}^{p_{0}} q(d p / g), u=(1 / w) \int_{0}^{p_{0}} q \hat{u}(d p / g)$, and $v=$ $(1 / w) \int_{0}^{p_{0}} q \hat{v}(d p / g)$. In this expression, $w$ is the amount of water vapor contained in a unit area column of air (precipitable water), $E$ is evaporation or source $\left(s_{o}\right)$ of water vapor into the column, and $P$ is precipitation or sink $\left(s_{i}\right)$ of water vapor out of the column. Notice that $u$ and $v$ are the vertically integrated and moistureweighted wind velocities, as opposed to $\hat{u}$ and $\hat{v}$, which are the actual wind velocities. Following a very similar argumentation as Dominguez et al. (2006), the recycled component of Eq. (3) (or green arrows in Fig. 2a) can be written as

$$
\frac{\partial\left(w_{m}\right)}{\partial t}+\frac{\partial\left(w_{m} u\right)}{\partial x}+\frac{\partial\left(w_{m} v\right)}{\partial y}=E-P_{m},
$$

where the subscript $m$ denotes the recycled component. Using the assumption of a well-mixed atmosphere, the definition of recycling ratio $\rho=w_{m} / w=P_{m} / P$, and the original mass conservation [Eq. (3)], we can rewrite Eq. (4) as

$$
w \frac{\partial \rho}{\partial t}+w u \frac{\partial \rho}{\partial x}+w v \frac{\partial \rho}{\partial y}=E-\rho P-\rho(E-P) .
$$

So Eq. (5) can now be written using the total derivative (as opposed to the partial derivative):

$$
\frac{d \rho}{d t}=\frac{E(1-\rho)}{w} .
$$

This is the DRM model, as derived by Dominguez et al. (2006). To analytically extract the contribution 
a)

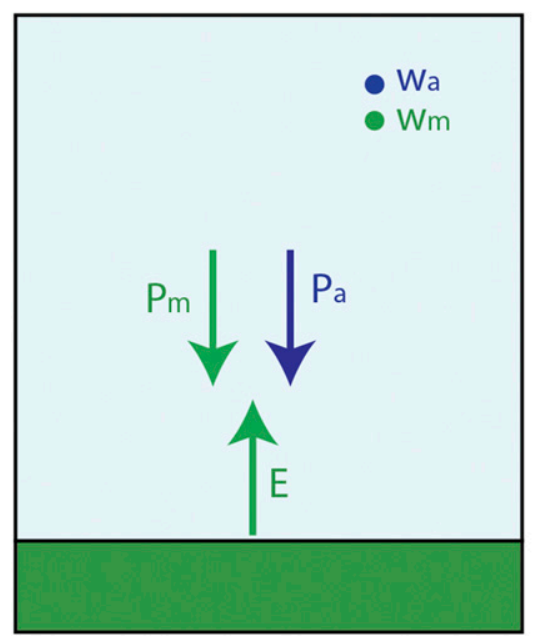

b)

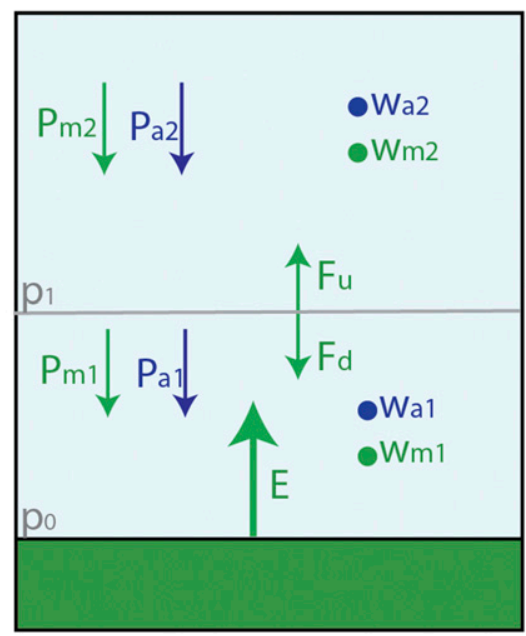

c)

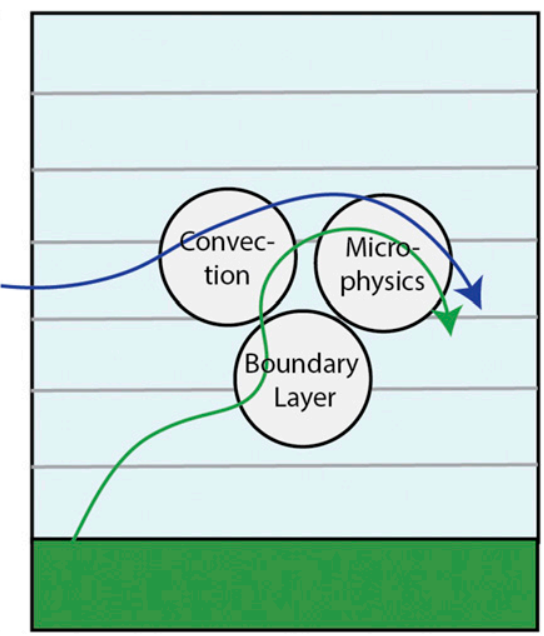

FIG. 2. Schematic depiction of (a) DRM, (b) 2L DRM, and (c)WRF-WVT, where $E$ is evapotranspiration, $P$ is precipitation, $w$ is precipitable water, and $F$ is the vertical flux of moisture in the upward $u$ or downward $d$ direction. Green colors and subscript $m$ denote fluxes and stores of atmospheric moisture originating from evapotranspiration within the region of analysis, while blue colors and subscript $a$ denote those of advection from outside the region. Gray lines denote different layers. Physical parameterizations within WRF-WVT are denoted by the white circles.

from different portions of the trajectory, Eq. (6) must be expanded using the equations presented in Martinez and Dominguez (2014).

\section{b. Two-layer dynamic recycling model (2L-DRM)}

As stated above, one of the main limitations with single slab models is that they perform poorly in regions of considerable shear. Consider, for example, the NAM region. Within the NAM, lower-level winds tend to come from west of the Sierra Madre Occidental, traversing the Gulf of California, while upper-level winds can come from the Gulf of Mexico and eastern Mexico, crossing the mountains into the core NAM region. The simple DRM described above defines the trajectories based on "moisture weighted winds," which results in back trajectories that are a mixture of trajectories at different levels, but that in some cases are not physically realistic (see, e.g., Figs. 3a,b and compare to Fig. 3c).

If we divide the atmosphere into two "slabs"; the first slab will extend between the surface $\left(p_{0}\right)$ and pressure level $1\left(p_{1}\right)$ and the second slab will extend between $p_{1}$ and the top of the atmosphere. We define $F^{u}$ as the upward vertical moisture flux at the interface of the slabs, which is 0 when the wind direction is downward. On the other hand, $F^{d}$ is the downward moisture flux, which is 0 when the wind direction is upward. In our calculations, we use the product of 6-hourly vertical velocity $\hat{w}$ and humidity $q$ at the interface of the slabs to calculate $F^{u}$ and $F^{d}$. This provides a first-order estimate of the "true" vertical moisture fluxes that occur due to turbulent fluxes. In lower-resolution numerical models, the convective parameterization and the boundary layer scheme will be responsible for the vertical redistribution of the moisture, but these vertical fluxes are not routinely saved. An alternative would be to use a moisture budget approach, which in our case gives very similar results (see appendix). However, analyses using coarser resolution simulations will likely require the moisture budget approach, as the resolved winds would underestimate the true fluxes.

The moisture conservation equation for the lower slab is written as

$$
\begin{aligned}
w_{1} \frac{d \rho_{1}}{d t}= & E+\rho_{2} F^{d}-\rho_{1} P_{1}-\rho_{1} F^{u} \\
& -\rho_{1}\left(E+F^{d}-P_{1}-F^{u}\right), \\
\frac{d \rho_{1}}{d t}= & \frac{E+\rho_{2} F^{d}}{w_{1}}-\rho_{1} \frac{E+F^{d}}{w_{1}},
\end{aligned}
$$

while the equation for the upper slab is

$$
\begin{aligned}
w_{2} \frac{d \rho_{2}}{d t} & =\rho_{1} F^{u}-\rho_{2} P_{2}-\rho_{2} F^{d}-\rho_{2}\left(F^{u}-P_{2}-F^{d}\right), \\
\frac{d \rho_{2}}{d t} & =\rho_{1} \frac{F^{u}}{w_{2}}-\rho_{2} \frac{F^{u}}{w_{2}} .
\end{aligned}
$$

It is important to point out that for the upper level, the definition of recycled precipitation is that which 

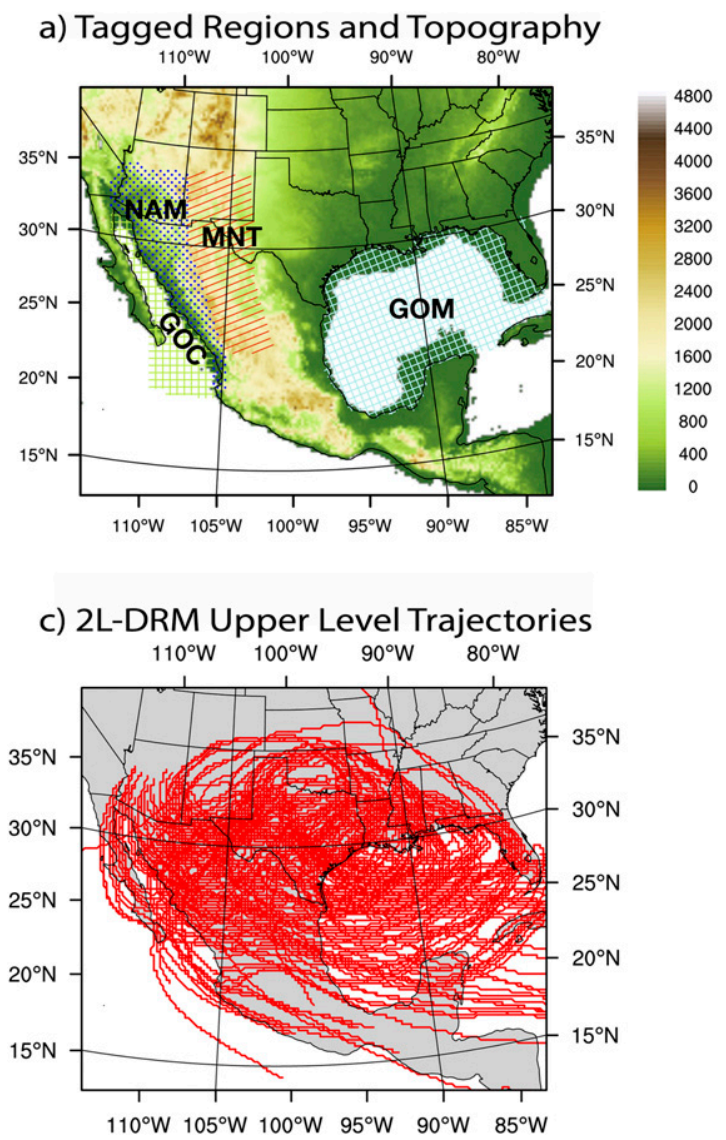

b) DRM Trajectories

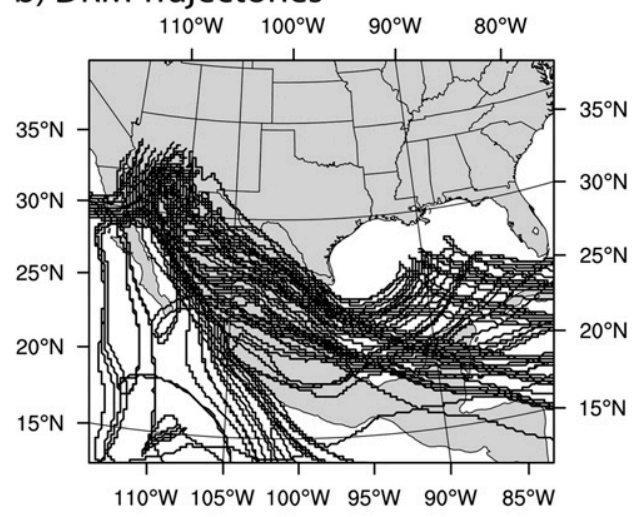

d) 2L-DRM Lower Level Trajectories

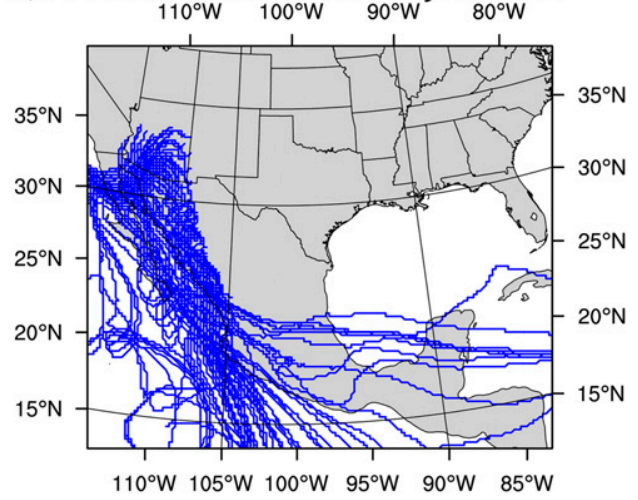

FIG. 3. (a) Topographical map showing the four individual source regions (GOM, GOC, NAM, and MNT). Examples of back trajectories originating from the NAM region on 18 Jul 2004 using (b) DRM, (c) 2L-DRM upper levels, (d) 2L-DRM lower levels.

originates as evapotranspiration from the lower level and is transported to the upper level via the vertical wind component.

\section{NUMERICAL IMPLEMENTATION OF 2L-DRM}

Based on the topography of the NAM region, and previous analysis that showed wind direction changes between 750 and $650 \mathrm{hPa}$ [see Fig. 11 of Dominguez et al. (2016)] we select $p_{1}=700 \mathrm{hPa}$ as the pressure level dividing the two slabs. When analyzing the sensitivity of the results to the cutoff level for one year (2004), we find very similar results using $p_{1}=600 \mathrm{hPa}$ or $p_{1}=800 \mathrm{hPa}$ for all regions except NAM, where recycling is slightly reduced from $12 \%$ to around $10 \%$ (not shown). This indicates that local recycling is somewhat sensitive to the cutoff level. However, we believe the best practice is to evaluate the characteristic wind profile in the region of analysis to select the cutoff level.

Much like the original DRM, the 2L-DRM uses back trajectories that are initialized once a day for every grid cell in the domain (and each of the two layers in the case of 2L-DRM as depicted in Figs. 3c,d). We trace the advected moisture back in time based on the moistureweighted winds, using the iterative numerical scheme described in Merrill et al. (1986). Tracking continues for a maximum of 15 days or until the trajectories exit the domain. The moisture contributions for the upper-level are calculated along the back trajectories using Eq. (10). This equation requires a priori information about $\rho_{1}$. To obtain this estimate we use the following equation $\rho_{1} w_{1}+\rho_{2} w_{2}=\rho\left(w_{1}+w_{2}\right)$, which provides an expression for $\rho_{1}$ in terms of $\rho$. We evaluate $\rho$ by assuming the same upper back trajectory would traverse the entire atmospheric column and applying Eq. (6). This can then be substituted in Eq. (10):

$$
\frac{d \rho_{2}}{d t}=\frac{w_{1}+w_{2}}{w_{1} w_{2}} \rho F^{u}-\rho_{2}\left(\frac{w_{1}+w_{2}}{w_{1} w_{2}} F^{u}\right)
$$

The same applies to the calculation along the lower back trajectory by replacing $\rho_{2}$ using $\rho$ obtained from 


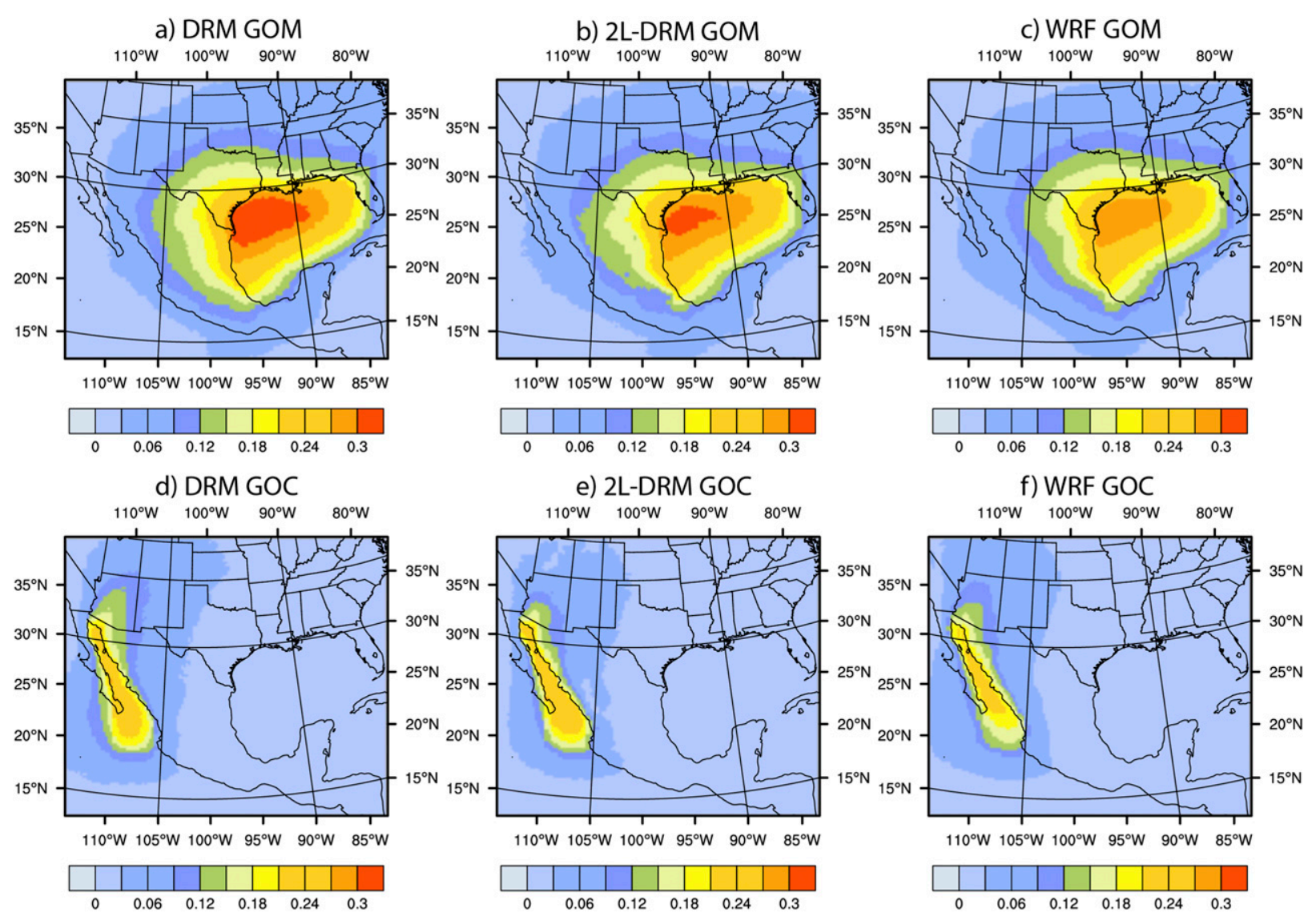

FIG. 4. Ten-year (2004-13) monsoon-season (June-October) averages of the fraction of total precipitable water originating from specific source regions (unitless). (a)-(c) The GOM source and (d)-(f) the GOC source using (left) DRM, (center) 2L-DRM, and (right) WRF-WVT. Estimates are based on backward trajectory calculations of the models.

the DRM assuming the same lower back trajectory would occur for the whole atmospheric column. This assumption is currently one of the major weaknesses in the 2L-DRM implementation because the same lower (upper) back trajectory is assumed when incorporating upper-lower exchange in calculating moisture contributions along the upper (lower) back trajectory.

\section{c. WRF-WVT}

The most physically realistic model we use in our study is the WRF-WVT. As explained in Insua-Costa and Miguez-Macho (2018), WRF-WVT tags the moisture that evaporates from a particular region and traces it in space and time, following the moisture budget equations in the dynamical core of the model, and including all physical parameterizations described in Eq. (1). This makes it different from other models where only water vapor is tagged, because WRF-WVT includes six different moisture species. The tracers are currently available for the Yonsei University planetary boundary layer scheme (Hong and Pan 1996), the WRF single-moment 6-class microphysics scheme (Hong and Lim 2006), the Noah LSM (Chen and Dudhia 2001), and the Kain-Fritsch convective parameterization Kain and Fritsch (1998). The details of the implementation of the tracers within each parameterization are explained in (Insua-Costa and Miguez-Macho 2018). The boundary conditions from the tracers can come from a 2D or a 3D source. Most of the applications of the work have used a 2D source (Dominguez et al. 2016; Yang et al. 2017) and have tagged the evapotranspiration fluxes from particular regions.

In this work, we use the WRF-WVT simulations described in Dominguez et al. (2016). The resolution of the simulations is $20 \mathrm{~km}$, with 26 vertical levels. Lateral boundary conditions come from the North American Regional Reanalysis (NARR) (Mesinger et al. 2006). The four regions that we have set as potential contributors to NAM precipitation are: the Gulf of California (GOC), the Gulf of Mexico (GOM), the NAM region, and the Sierra Madre mountains (MNT) (see Fig. 3). 

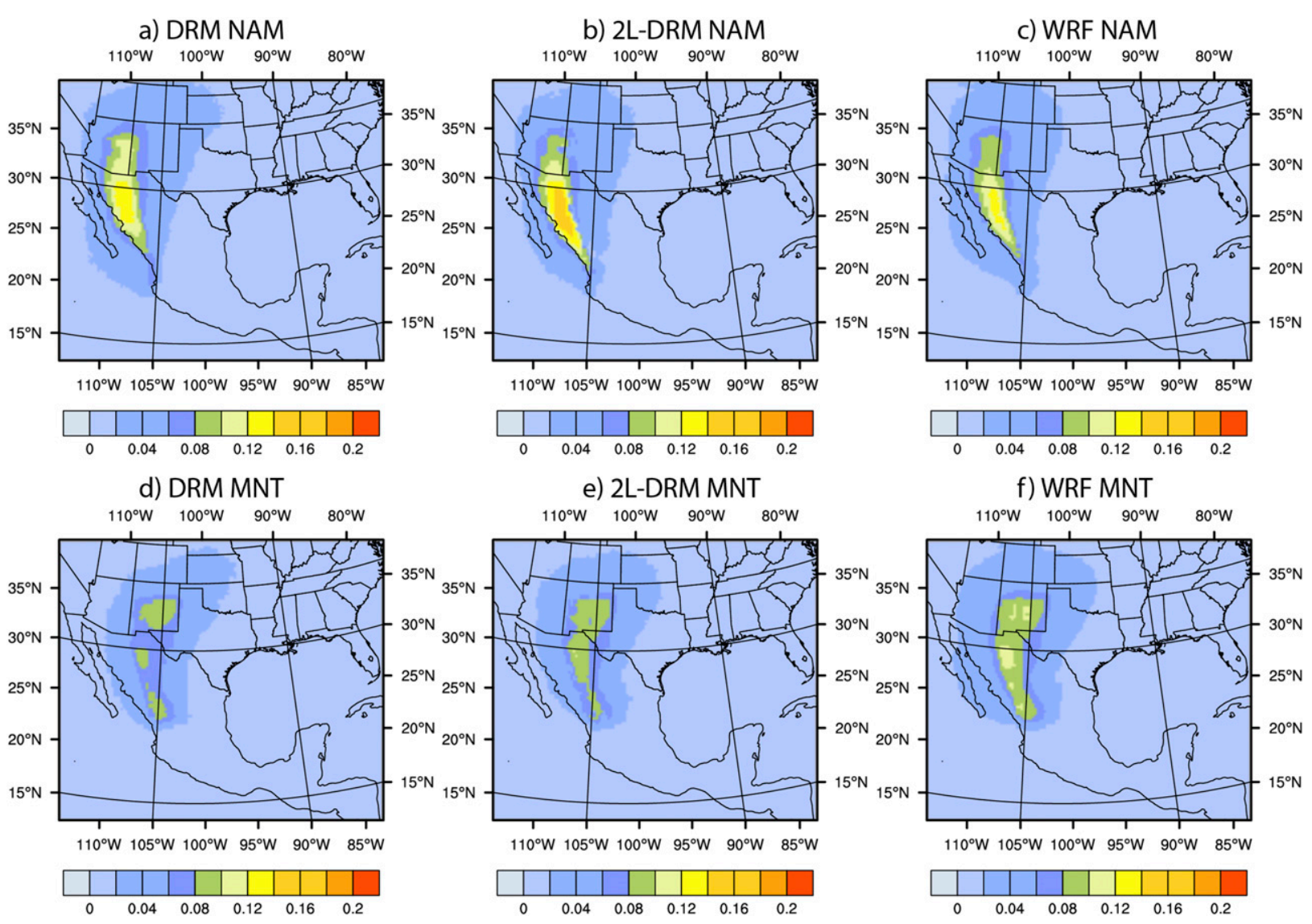

FIG. 5. As in Fig. 4, but evaluating the moisture contribution from the (a)-(c) NAM region and (d)-(f) MNT region.

\section{Results}

The results from WRF-WVT, in terms of water vapor and precipitation originating from the four tagged regions, are treated as the truth in our analysis. In other words, we will compare the performance of the simple DRM and 2L-DRM and evaluate how similar/different these simulated moisture sources are compared to WRF-WVT. We also use the specific humidity, winds, precipitation and evapotranspiration from the 10-yr WRF-WVT simulations as input to the DRM and 2L-DRM. Note that we are not using the tagged water as input to the simple models, only the fields that would be available from other sources such as reanalyses or climate model data.

The moisture originating from oceanic sources (GOC and GOM) averaged over the 10 -yr simulation is shown in Fig. 4. The spatial extent of the moisture originating from the GOM during the June-October period extends throughout the southeastern United States and eastern Mexico and penetrates into the core NAM region (Figs. $4 \mathrm{a}-\mathrm{c}$ ). The DRM overestimates the magnitude of moisture originating from the GOM, particularly over the GOM itself, as compared to WRF-WVT.
The amount of moisture is better captured by 2L-DRM, although some overestimation still persists. A similar overestimation by the DRM is evident for the moisture originating from the GOC (comparing Fig. 4d with Fig. 4f), particularly in terms of the penetration of GOC moisture into Arizona. The 2L-DRM estimation lies somewhere in between WRF-WVT and the DRM, showing less inland penetration than the DRM.

Terrestrial moisture sources also significantly contribute to monsoonal precipitation; however, WRF-WVT suggests less recycling (precipitation originating from NAM) than the DRM estimates (Figs. 5a-c). In this case, the 2L-DRM has even higher recycling estimates than the simple DRM. However, the spatial extent is more similar to the WRF-WVT, particularly in regions of Oklahoma and Kansas. The moisture originating from the Sierra Madre (MNT) is underestimated in the DRM, and in this case, the 2L-DRM improves the amount and spatial extent of the simple DRM (Figs. 5d-f) with more significant moisture of MNT origin throughout the region.

During the NAM season, the largest differences between the DRM, 2L-DRM, and WRF-WVT occur at the beginning of the season between mid-June and late July 
a) Climatological Seasonal Cycle of the Ratio of PW in NAM from Tracer Region to total PW in NAM region.

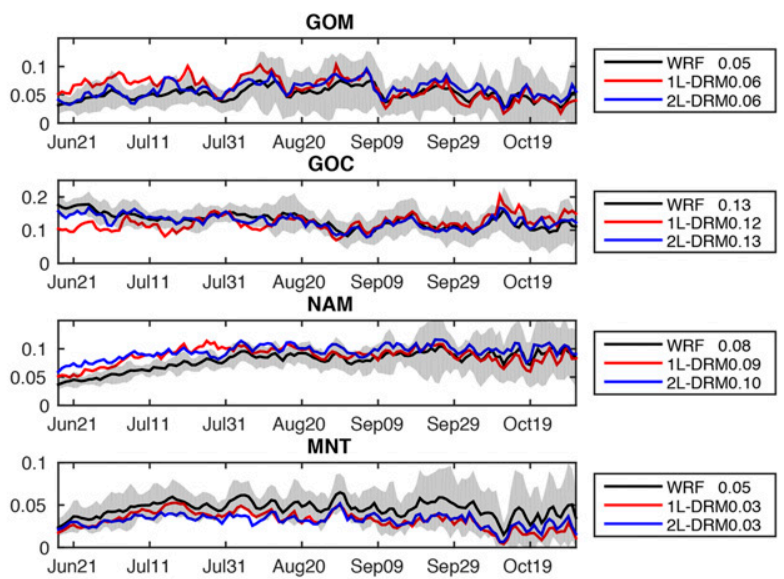

b) Climatological Seasonal Cycle of the Ratio of Precipitation in NAM from Tracer Region to total Precipitation in NAM region.
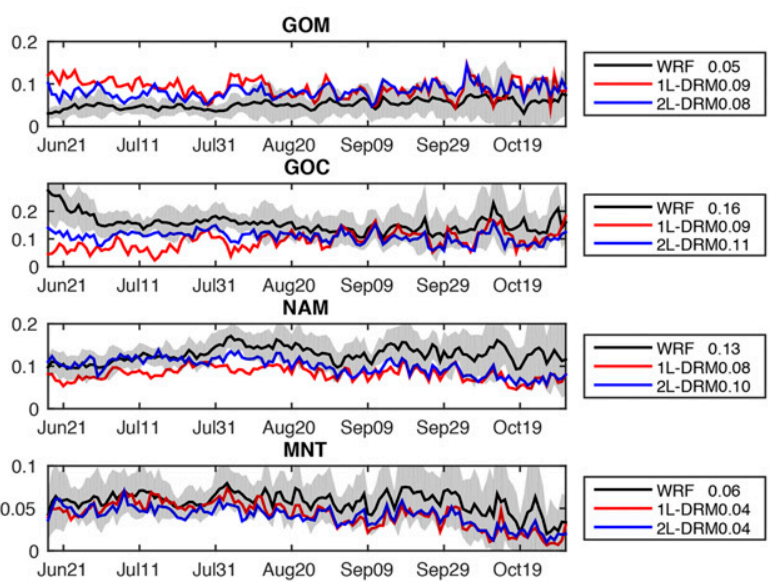

FIG. 6. Ten-year monsoon-season averages of moisture contributions from different regions to the NAM region: (a) the ratio based on precipitable water (PW) and (b) the ratio based on precipitation. All the results are area-averaged over the NAM region. The legend on the right shows the average fraction of moisture contributed by each source region. Shading denotes one standard deviation of the WRF-WVT simulation.

(Fig. 6). When quantifying the moisture contributions to the NAM region, the DRM overestimates the precipitable water (PW) and precipitation contribution from GOM, while the 2L-DRM estimate is very similar to the WRF-WVT estimate in terms of PW (Fig. 6a) and somewhere in between the DRM and WRF-WVT in terms of precipitation (Fig. 6b). Conversely, the early-season contribution from the GOC, as quantified with WRF-WVT, is clearly larger than the DRM estimate. The 2L-DRM corrects the DRM subestimation and is very close to the WRF-WVT values using PW ratios (Fig. 6a) and the improvement is also visible when looking at precipitation (Fig. 6b).
TABLE 1. Climatological mean contribution of evapotranspiration from within the source regions (GOM, GOC, NAM, and MNT) to precipitable water and precipitation within the NAM region. Results are averaged over the 10-yr period for the months of June-October, and area-averaged over the NAM region. The number in parentheses is the standard deviation based on daily data.

\begin{tabular}{llll}
\hline \hline Region & \multicolumn{1}{c}{ DRM } & 2L-DRM & WRF-WVT \\
\hline \multicolumn{5}{c}{ Precipitable water } \\
GOM & $0.06(0.05)$ & $0.06(0.04)$ & $0.05(0.04)$ \\
GOC & $0.12(0.06)$ & $0.13(0.05)$ & $0.13(0.04)$ \\
NAM & $0.09(0.04)$ & $0.10(0.04)$ & $0.08(0.03)$ \\
MNT & $0.03(0.02)$ & $0.03(0.02)$ & $0.05(0.02)$ \\
\multicolumn{4}{c}{ Precipitation } \\
GOM & $0.09(0.08)$ & $0.08(0.06)$ & $0.05(0.04)$ \\
GOC & $0.09(0.09)$ & $0.11(0.07)$ & $0.16(0.07)$ \\
NAM & $0.08(0.04)$ & $0.10(0.04)$ & $0.13(0.05)$ \\
MNT & $0.04(0.03)$ & $0.04(0.03)$ & $0.06(0.03)$ \\
\hline
\end{tabular}

During the mid and late seasons, the three estimates are indistinguishable.

The estimation of the PW that originates as NAM terrestrial evapotranspiration shows very similar values between the DRM and 2L-DRM, and both overestimate the importance of water vapor of local origin in the early season (Fig. 6a). During the late season, the three estimates are very similar. When looking at precipitation (Fig. 6b), the 2L-DRM estimate of local recycling (the contribution of NAM evapotranspiration to NAM precipitation) is very similar to the WRF-WVT estimate in the early season, while it diverges toward the DRM estimate in the late season. This is interesting, because the comparison of the WRF-WVT PW to precipitation time series shows that the local water vapor originating from NAM is being more efficiently rained out than the remote water vapor and $2 \mathrm{~L}-\mathrm{DRM}$ is mimicking this behavior (during the early season) while DRM cannot capture the fast recycling mechanism. On the other hand, both simple models seem to underestimate the PW and precipitation contribution from the mountains (MNT) (Figs. 6a,b) throughout the season.

The 10-yr average contribution from each region, for each model, is summarized in the right panels of Fig. 6 and in Table 1, which includes the standard deviation of the estimate. It is clear that the three models (ranging from simple to complex) give very similar estimates of the contributions. All three models give the same ranking of the moisture sources for precipitable water: GOC has the highest contribution, local recycling from NAM follows, then the contribution from the GOM and the smallest contribution is from MNT. The ranking for precipitation is the same, but the DRM ranks GOM second (emphasizing the issue with wind shear). This implies that when averaged in space and time, the models 


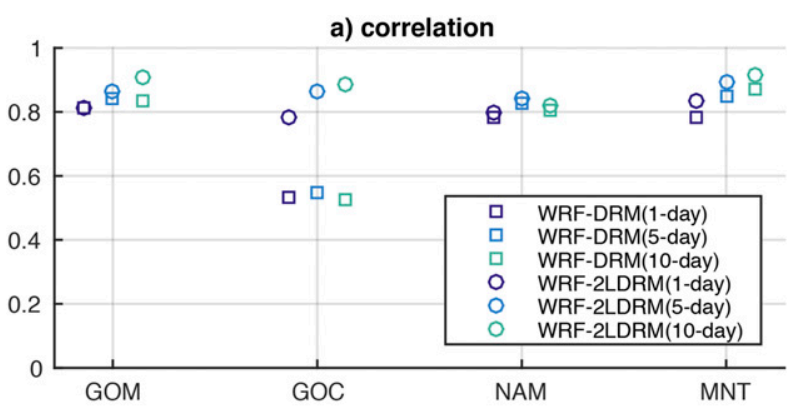

b) slope

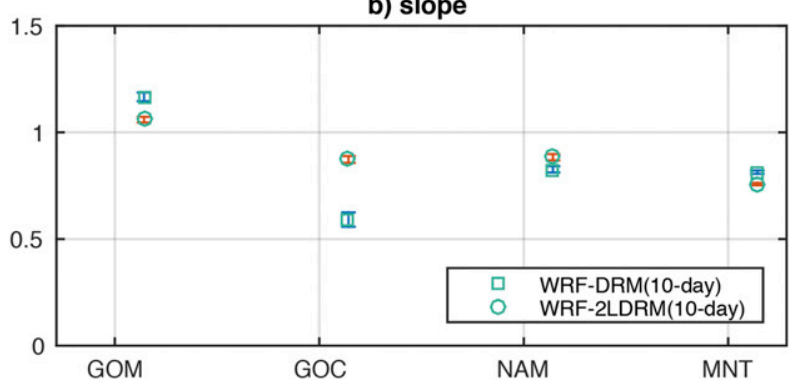

FIG. 7. (a) Temporal correlation between the time series of WRF-WVT and DRM (squares) and WRF-WVT and 2L-DRM (circles) for the four source regions ( $x$ axis) at three different temporal resolutions of 1,5 , and 10 days. (b) Slope $a$ of the linear regression DRM $=a \times \mathrm{WRF}-\mathrm{WVT}+b$ (squares) and 2L-DRM $=$ $a \times \mathrm{WRF}-\mathrm{WVT}+b$ (circles) for the four source regions ( $x$ axis) at 10 -day temporal resolution. The standard error of the slope is plotted in blue and red.

behave in a very similar way and provide comparable estimates.

The differences between the three models start to become evident when moving away from spatial and temporal averages. The correlation of the PW contribution between DRM and WRF-WVT and between 2L-DRM and WRF-WVT from each of the four regions is shown in Fig. 7. The correlations between 2L-DRM and WRF-WVT are very high, mostly exceeding 0.8 for 1-, 5-, and 10-day correlations. The correlation of DRM and WRF-WVT are also very high, except for the moisture coming from GOC. The correlations for GOC are below 0.6 for all temporal scales of averaging. This indicates that neglecting the vertical shear will result in an incorrect temporal characterization of the moisture sources from the GOC. The bottom panel of Fig. 7 shows the slope of the linear regression between WRF-WVT and both simple models. In the case of GOM, GOC, and NAM, the slope of the $2 \mathrm{~L}-\mathrm{DRM}$ is closer to 1 , indicating that the $2 \mathrm{~L}$-DRM is better capturing the fluctuations in moisture transport from these regions. This is particularly evident in GOC, where the improvement is significant, as can be seen when comparing the change with the standard error of the slope estimate. Both simple models overestimate the fluctuations in the moisture coming from GOM, as the slope is greater than 1 . While both simple models underestimate the fluctuations (variability) in the moisture coming from GOC, NAM, and MNT.

The difference between DRM and 2L-DRM is perhaps best captured when analyzing an individual event. As an example, we show the moisture contributions from GOM and GOC during a 5-day period from 16 to 20 July 2004 (Fig. 8). This case is representative of the early monsoon season. During this time, the DRM estimates a much greater contribution from GOM to the monsoon region than WRF-WVT. The reason, as alluded to earlier when discussing Fig. 3, is because the DRM back trajectories move from southeast to northwest and hence bring significant moisture from the GOM. However, WRF-WVT shows that in reality the Sierra Madre Mountains block this moisture and impede its passage into the NAM region. The 2L-DRM captures this behavior quite well. DRM also estimates a large contribution of GOC moisture into the continental United States including Utah and Colorado, while both 2L-DRM and WRF-WVT limit the GOC moisture penetration mostly to Arizona.

\section{Discussion and conclusions}

Simple analytical 2D models of moisture sources and sinks rely on the assumption of complete vertical mixing. When compared to more complex models, it is clear that the complete vertical mixing assumption leads to an incorrect depiction of the vertical height from where water vapor contributes to precipitation and an incorrect direction of moisture fluxes in regions of strong vertical shear such as the NAM region (see Fig. 3) or the Sahel (VE2013). In this work we address the second deficiency by mathematically deriving the new 2L-DRM, a twolayer analytical recycling model which is an extension of the original DRM (Dominguez et al. 2006; Martinez and Dominguez 2014) We then analyze the sources and sinks of moisture for the NAM region using three models of different complexity: DRM, 2L-DRM, and WRF-WVT. The analysis is done using a 10-yr climatological WRF simulation of the NAM. WRF-derived winds, moisture, evapotranspiration and precipitation are used to drive the two analytical models. In addition, the WRF simulations have embedded water vapor tracers (WRF-WVT) that we treat as the truth.

Our results show that the oceanic sources of moisture from the GOM and GOC are more realistically captured in the 2L-DRM than in the DRM, when compared to the WRF-WVT. The climatological spatial extent, the net amount of precipitation of oceanic origin, and the temporal variability is better captured by the two-layer model. During the early monsoon season, the DRM 
a) DRM GOC

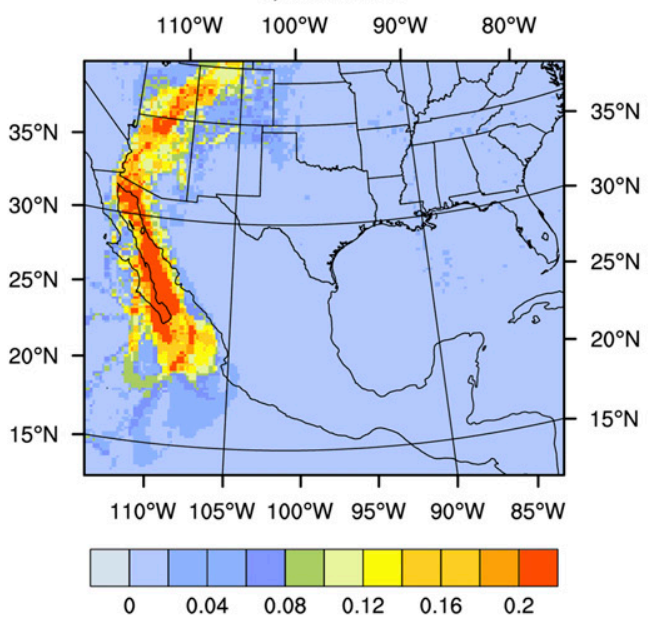

c) 2L-DRM GOC

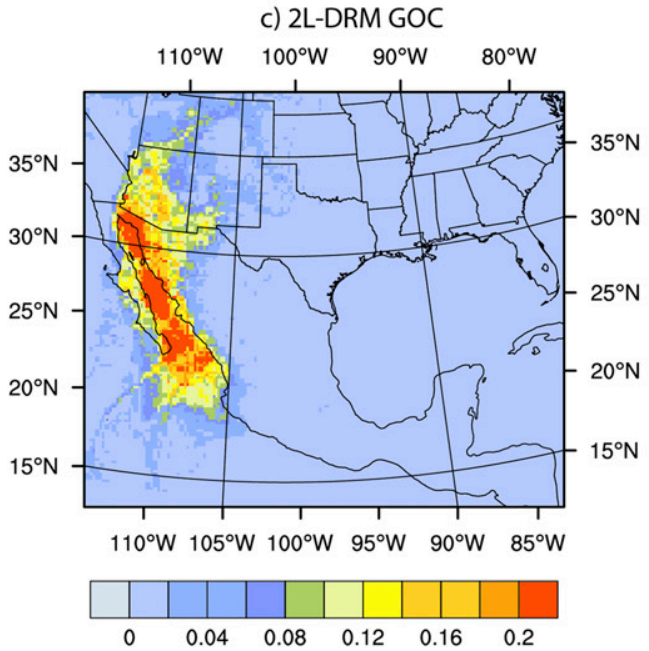

e) WRF GOC

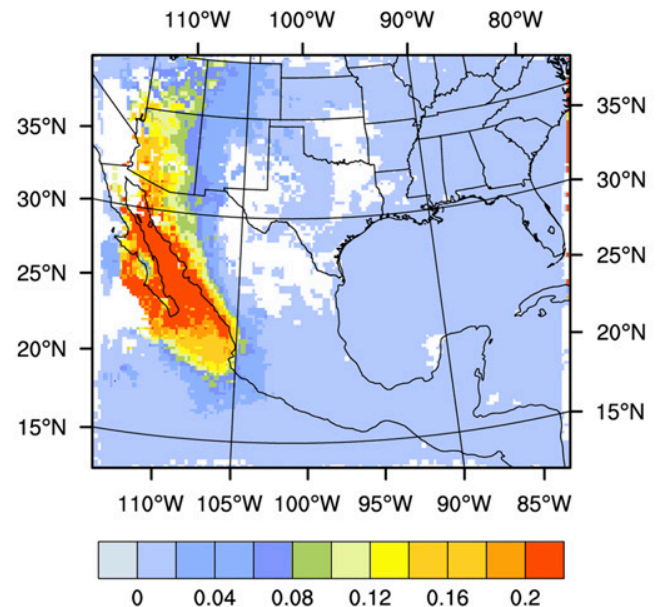

b) DRM GOM

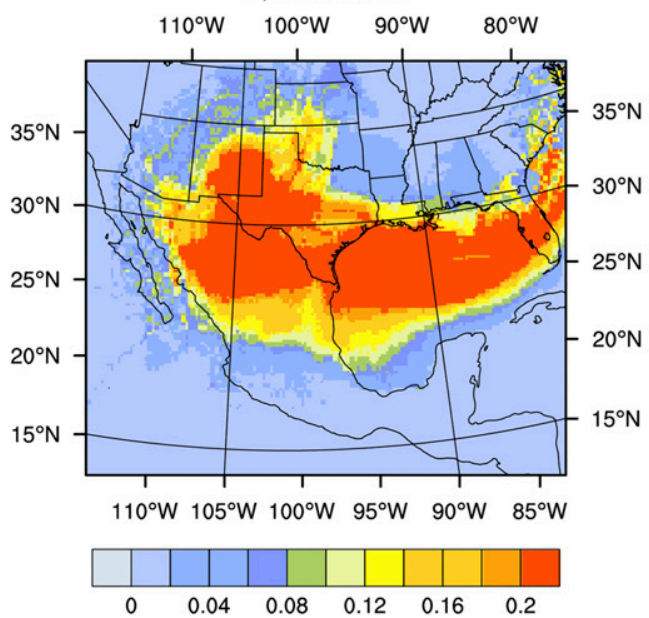

d) 2L-DRM GOM

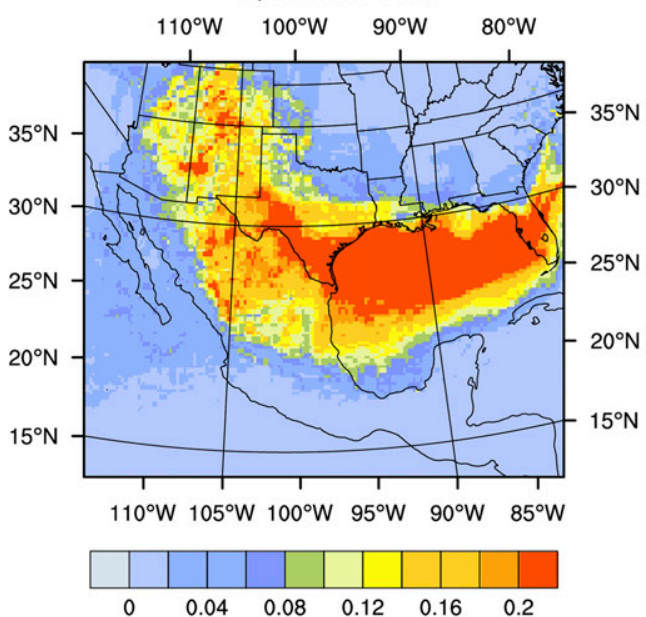

f) WRF GOM

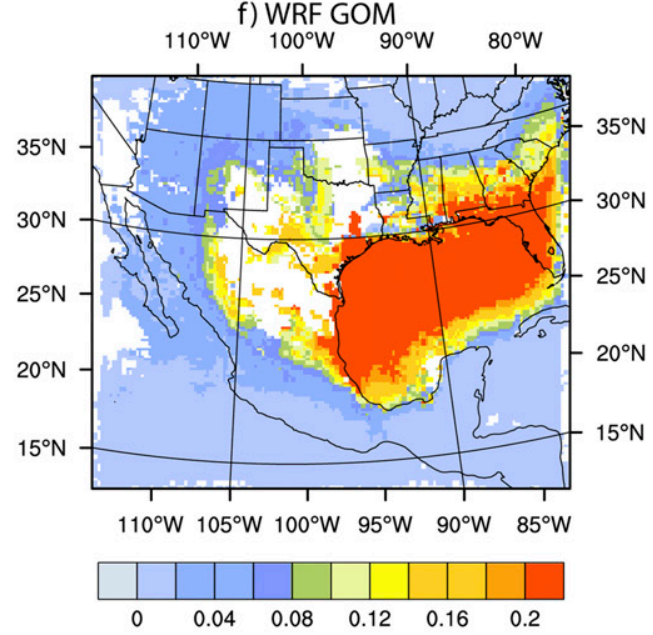

FIG. 8. The 16-20 Jul 2004 5-day average unitless fraction of total precipitation coming from the (left) GOC and (right) GOM as calculated by (a),(b) DRM; (c),(d) 2L-DRM; and (e),(f) WRF-WVT. White areas represent regions of no precipitation. 
overestimates the moisture from the GOM and underestimates GOC moisture contributions. The reason is that the DRM back tracks the moisture fluxes using moisture weighted winds. In the case of the early monsoon season, the moisture is back tracked from the east (biased by the strong easterly high-level winds that cross the Sierra Madre). In reality, most of the moisture resides in the lower atmosphere and is in part contributed by the GOC, advected by southwesterly winds (see Fig. 3). The 2L-DRM is able to separate the upper-level and lower-level winds and more realistically capture the moisture contributions (as depicted in WRF-WVT). After July, however, the three models are largely indistinguishable in terms of their area-average oceanic moisture contributions to the NAM (Fig. 6).

In terms of the terrestrial sources of moisture, we have seen that the WRF-WVT highlights the process of fast recycling where the moisture of local origin is preferentially rained out of the column. Notice, for example that WRF calculates the ratio of precipitable water of NAM origin to total precipitable water as $8 \%$, but nearly $13 \%$ of the total precipitation is of NAM origin (Fig. 6). The DRM cannot capture this process and underestimates the precipitation of local origin (recycled precipitation). The $2 \mathrm{~L}-\mathrm{DRM}$, on the other hand is able to capture the fast recycling on NAM moisture in the early season (with high estimates of precipitation of local origin, which are in line with the WRF estimates), although late-season recycling is underestimated. In addition, both simple models are underestimating the contribution from the adjacent mountainous regions (MNT) throughout the season. It is likely that several factors are contributing to these biases in moisture from the mountains. Part of the reason, is the complex nature of monsoonal precipitation. Convective precipitation in the monsoon region begins in the mountainous regions in the early afternoon, then transitions into deep convection and organizes into systems that bring intense precipitation west of the mountains throughout the monsoon region (Nesbitt et al. 2008). To the extent that the Kain-Fritsch convective parameterization in WRF-WVT captures these processes, the complex model estimates indicate that the moisture from the mountains is significantly contributing to these systems. However, the very simple DRM or 2L-DRM are not able to capture the complexities of these convective systems and their interactions with the local terrain or how moisture is redistributed in the vertical column because of deep convection.

It is important to emphasize that the choice of model to quantify sources and sinks of moisture depends on the goal of the study. Simple analytical models are well suited to study the large-scale climatological sources of moisture because these models are flexible in the type of input data and computationally very efficient (VE2013). In our study it is clear that the three methods yield very similar results when looking at the 10 -yr climatology, as all the details are masked in the averaging process. If the user is interested in a bulk quantification of moisture sources, then analytical models are ideal. The computational difference between the 2L-DRM and DRM is negligible, so we recommend using the two-layer version to account for vertical shear. On the other hand, the power of complex models is evident when analyzing individual cases/seasons where the local-scale processes are important. Furthermore, the new models such as WRF-WVT can be applied at the convective resolving scale, and will allow us to delve into the details of moisture transport for processes that are not resolvable at coarser resolutions (such as convective initiation and organization). It is clear that vertical height from where water vapor contributes to precipitation is not proportional to the level's mixing ratio, however, we have yet to find an adequate and elegant way to represent this in simple models. Perhaps the new tools of water vapor tracers at the convective resolving scale can help us further improve the simple models and gain improved conceptual understanding (Held 2005) of the physical processes related to vertical moisture redistribution and precipitation.

Acknowledgments. This research was supported by National Science Foundation (NSF) CAREER Award AGS 1454089. Hu is supported by the U.S. Department of Energy Office of Science Biological and Environmental Research as part of the Regional and Global Climate Modeling program. PNNL is operated for the Department of Energy by Battelle Memorial Institute under contract DE-AC05-76RL01830. Support for Martinez comes from Comité Desarrollo Investigación (CODI) Award 2017-16264. We thank G. Miguez-Macho for providing the WRF-WVT code and Dr. Ir. Ruud van der Ent and an anonymous reviewer for providing valuable comments to improve the manuscript. The source code for DRM and 2L-DRM used for this work can be accessed by https://github.com/huancui/DRM_2LDRM.

\section{APPENDIX}

\section{Vertical Fluxes at Interface}

The calculation of the recycling ratios depends on the moisture fluxes at the interface of the two slabs [Eqs. (8) and (10)]. In the real world, this process occurs due to turbulent fluxes. In lower-resolution numerical models, the convective parameterization and the boundary layer 
a) qw budget

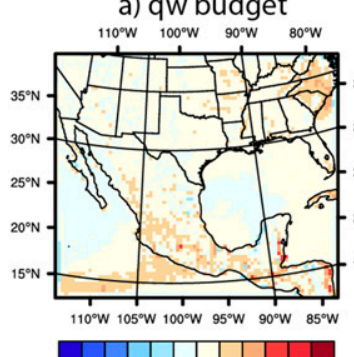

$\begin{array}{llllllllllllll}-10 & -8 & -6 & -4 & -2 & 0 & 2 & 4 & 6 & 8 & 10\end{array}$

c) GOM qw budget

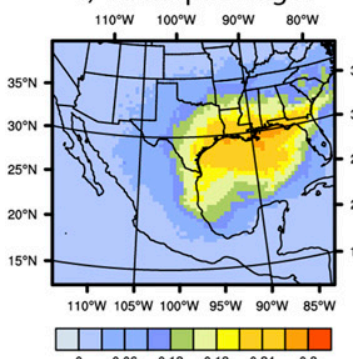

\begin{tabular}{llllllll}
\hline & 0.06 & 0.12 & 0.18 & 0.24 & 0.3
\end{tabular}

f) GOC qw budget

$10^{\circ} \mathrm{W} \quad 100^{\circ} \mathrm{W} \quad 90^{\circ} \mathrm{W} \quad 80^{\circ} \mathrm{W}$

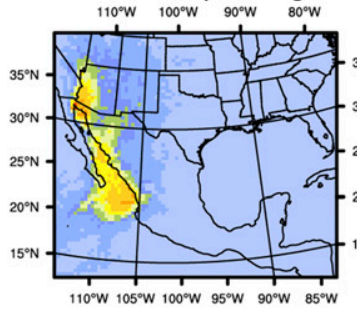

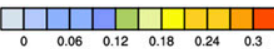

i) NAM qw budget

$110^{\circ} \mathrm{W} \quad 100^{\circ} \mathrm{W} \quad 90^{\circ} \mathrm{W}$

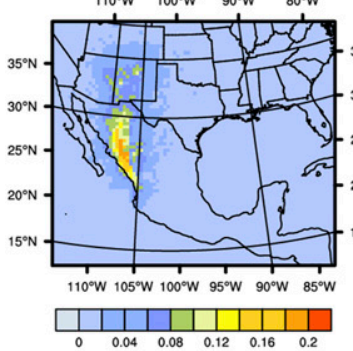

I) MNT qw budget

$110^{\circ} \mathrm{W} 100^{\circ} \mathrm{W} 90^{\circ} \mathrm{W} \quad 80^{\circ} \mathrm{W}$

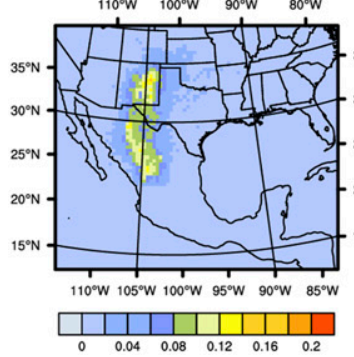

b) $\bar{q} \bar{w}$

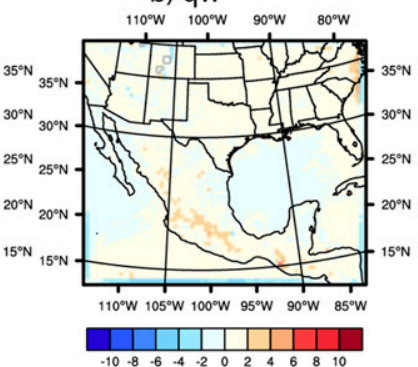

d) GOM $\bar{q} \bar{w}$

$110^{\circ} \mathrm{W} \quad 100^{\circ} \mathrm{W} \quad 90^{\circ} \mathrm{W} \quad 80^{\circ} \mathrm{W}$

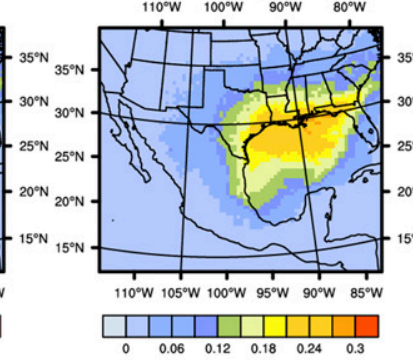

g) GOC $\bar{q} \bar{w}$

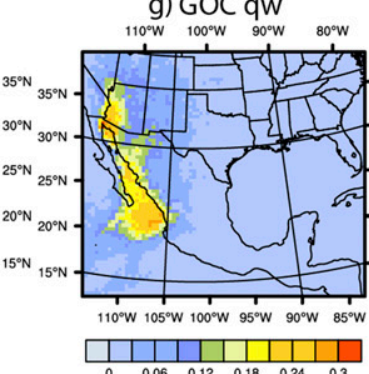

j) NAM $\bar{q} \bar{w}$

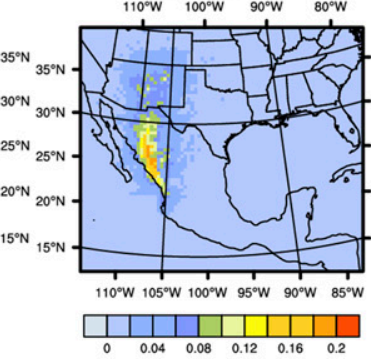

m) MNT $\bar{q} \bar{w}$

$110^{\circ} \mathrm{W} \quad 100^{\circ} \mathrm{W} \quad 90^{\circ} \mathrm{W} \quad 80^{\circ} \mathrm{W}$

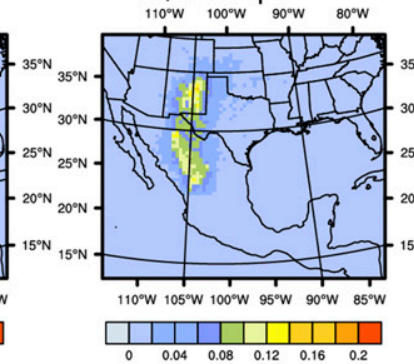

e) GOM diff

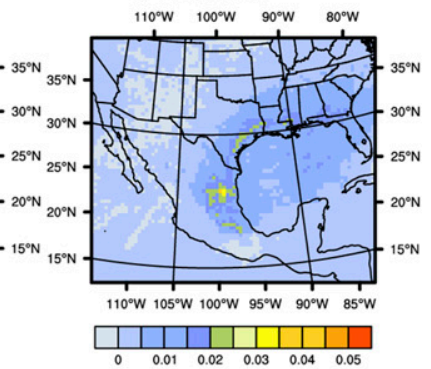

h) GOC diff

$110^{\circ} \mathrm{W} \quad 100^{\circ} \mathrm{W} \quad 90^{\circ} \mathrm{W} \quad 80^{\circ} \mathrm{W}$

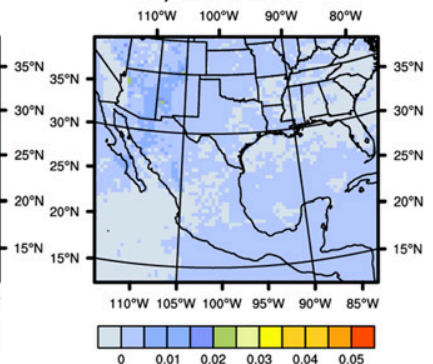

k) NAM diff

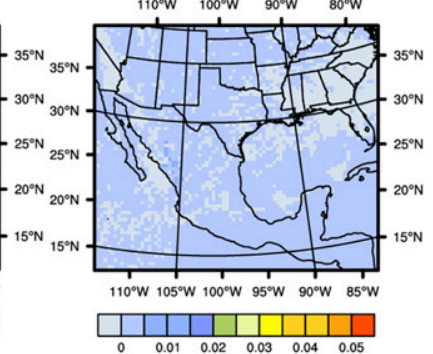

n) MNT diff

$110^{\circ} \mathrm{W} \quad 100^{\circ} \mathrm{W} \quad 90^{\circ} \mathrm{W} \quad 80^{\circ} \mathrm{W}$

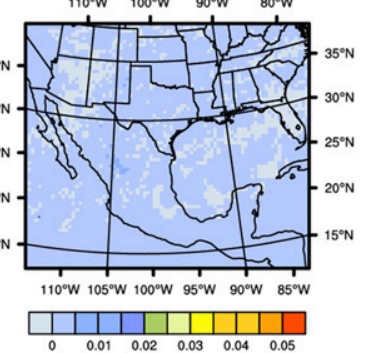

FIG. A1. Comparison of moisture fluxes. Shown are (a) $q w$ at $700 \mathrm{hPa}$ (and $w$ is the vertical velocity) calculated using the water budget method and (b) $\bar{q} \bar{w}$ for June $2004\left(\mathrm{~g} \mathrm{~kg}^{-1} \mathrm{~m} \mathrm{~s}^{-1}\right)$. (c),(f),(i),(l) The fraction of moisture contribution from different source regions using $q w$ calculated from the water budget method; $(\mathrm{d}),(\mathrm{g}),(\mathrm{j}),(\mathrm{m})$ the fraction of moisture contribution from different source regions using $\bar{q} \bar{w}$; and (e),(h),(k),(n) the difference (left column minus center column). 
scheme will be responsible for the vertical redistribution of the moisture. However, the vertical moisture flux at high resolution is not routinely saved in models. One way to quantify the vertical moisture flux is by using the moisture budget, where the vertical moisture flux is calculated as the residual of the moisture budget equation in each time step. We performed a series of trials to quantify the difference between the vertical moisture flux calculated using the moisture budget method from that using the product of 6-hourly $\hat{w}$ and $q$ at $700 \mathrm{hPa}$ for the month of June 2004. The results are shown in Fig. A1, where the first column shows the vertical fluxes and moisture sources using the budget method, the second column shows the fluxes and moisture sources from the model derived instantaneous fluxes, and the third column shows the difference. The difference in the two methods of estimating the flux is particularly evident close to the Sierra Madre in Mexico and the tropical Pacific Ocean, as one would expect (see first row of Fig. A1). However, when calculating the difference between the moisture contributions from the different regions the differences (shown in Figs. A1e,h,k,n) are very small. For this reason, we decided to use the instantaneous product of 6-hourly $\hat{w}$ and $q$ at $700 \mathrm{hPa}$ to calculate the vertical fluxes. It is interesting to note, however, that the differences are largely positive throughout the domain. This indicates that, using the resolved fluxes underestimates the transport above $700 \mathrm{hPa}$ and overestimates the moisture in the lower layer.

\section{REFERENCES}

Arnault, J., R. Knoche, J. Wei, and H. Kunstmann, 2016: Evaporation tagging and atmospheric water budget analysis with WRF: A regional precipitation recycling study for West Africa. Water Resour. Res., 52, 1544-1567, https://doi.org/ 10.1002/2015WR017704.

Bosilovich, M., 2002: On the vertical distribution of local and remote sources of water for precipitation. Meteor. Atmos. Phys., 80, 31-41, https://doi.org/10.1007/s007030200012.

— , and S. D. Schubert, 2001: Precipitation recycling over the central United States diagnosed from the GEOS-1 data assimilation system. J. Hydrometeor., 2, 26-35, https://doi.org/ 10.1175/1525-7541(2001)002<0026:PROTCU > 2.0.CO;2.

—, Y. Sud, S. Schubert, and G. Walker, 2003: Numerical simulation of the large-scale North American monsoon water sources. J. Geophys. Res., 108, 8614, https://doi.org/10.1029/ 2002JD003095.

Brubaker, K. L., D. Entekhabi, and P. S. Eagleson, 1993: Estimation of continental precipitation recycling. J. Climate, 6, 1077-1089, https://doi.org/10.1175/1520-0442(1993)006<1077: EOCPR $>2.0 . \mathrm{CO} ; 2$.

Budyko, M. I., 1974: Climate and Life. Academic Press, 508 pp.

Burde, G. I., and A. Zangvil, 2001: The estimation of regional precipitation recycling. Part II: A new recycling model. J. Climate, 14, 2509-2527, https://doi.org/10.1175/15200442(2001)014<2509:TEORPR >2.0.CO;2.
Chen, F., and J. Dudhia, 2001: Coupling an advanced land surface-hydrology model with the Penn State-NCAR MM5 modeling system. Part I: Model implementation and sensitivity. Mon. Wea. Rev., 129, 569-585, https://doi.org/10.1175/ 1520-0493(2001)129<0569:CAALSH > 2.0.CO;2.

de Leeuw, J., J. Methven, and M. Blackburn, 2017: Physical factors influencing regional precipitation variability attributed using an airmass trajectory method. J. Climate, 30, 7359-7378, https:// doi.org/10.1175/JCLI-D-16-0547.1.

Dirmeyer, P. A., and K. L. Brubaker, 2007: Characterization of the global hydrologic cycle from a back-trajectory analysis of atmospheric water vapor. J. Hydrometeor., 8, 20-37, https:// doi.org/10.1175/JHM557.1.

Dominguez, F., P. Kumar, X. Liang, and M. Ting, 2006: Impact of atmospheric moisture storage on precipitation recycling. J. Climate, 19, 1513-1530, https://doi.org/10.1175/JCLI3691.1.

, - - and E. R. Vivoni, 2008: Precipitation recycling variability and ecoclimatological stability-A study using NARR data. Part II: North American monsoon region. J. Climate, 21, 5187-5203, https://doi.org/10.1175/2008JCLI1760.1.

_ G. Miguez-Macho, and H. Hu, 2016: WRF with water vapor tracers: A study of moisture sources for the North American monsoon. J. Hydrometeor., 17, 1915-1927, https://doi.org/ 10.1175/JHM-D-15-0221.1.

Drozdov, O. A., and A. S. Grigor'eva, 1965: The Hydrologic Cycle in the Atmosphere. Israel Program for Scientific Translations, $282 \mathrm{pp}$.

Eltahir, E. A. B., and R. L. Bras, 1996: Precipitation recycling. Rev. Geophys., 34, 367-378, https://doi.org/10.1029/96RG01927.

Gimeno, L., and Coauthors, 2012: Oceanic and terrestrial sources of continental precipitation. Rev. Geophys., 50, RG4003, https:// doi.org/10.1029/2012RG000389.

Goessling, H. F., and C. H. Reick, 2011: What do moisture recycling estimates tell us? Exploring the extreme case of non-evaporating continents. Hydrol. Earth Syst. Sci., 15, 3217-3235, https://doi.org/10.5194/hess-15-3217-2011.

—, and — 2013: On the "well-mixed" assumption and numerical 2-D tracing of atmospheric moisture. Atmos. Chem. Phys., 13, 5567-5585, https://doi.org/10.5194/acp-13-5567-2013.

Gustafsson, M., D. Rayner, and D. Chen, 2010: Extreme rainfall events in southern Sweden: where does the moisture come from? Tellus, 62A, 605-616, https://doi.org/10.1111/j.16000870.2010.00456.x.

Held, I. M., 2005: The gap between simulation and understanding in climate modeling. Bull. Amer. Meteor. Soc., 86, 1609-1614, https://doi.org/10.1175/BAMS-86-11-1609.

Hong, S.-Y., and H.-L. Pan, 1996: Nonlocal boundary layer vertical diffusion in a medium-range forecast model. Mon. Wea. Rev., 124, 2322-2339, https://doi.org/10.1175/15200493(1996)124<2322:NBLVDI>2.0.CO;2.

- , and J. Lim, 2006: The WRF Single-Moment 6-Class Microphysics Scheme (WSM6). J. Korean Meteor. Soc., 42 (2), 1-23.

Hu, H., and F. Dominguez, 2015: Evaluation of oceanic and terrestrial sources of moisture for the North American monsoon using numerical models and precipitation stable isotopes. J. Hydrometeor., 16, 19-35, https://doi.org/10.1175/JHM-D-14-0073.1.

Insua-Costa, D., and G. Miguez-Macho, 2018: A new moisture tagging capability in the Weather Research and Forecasting model: Formulation, validation and application to the 2014 Great Lake-effect snowstorm. Earth Syst. Dyn., 9, 167-185, https://doi.org/10.5194/esd-9-167-2018.

Joussaume, S., R. Sadourny, and J. Jouzel, 1984: A general-circulation model of water isotope cycles in the atmosphere. Nature, 311, 24-29, https://doi.org/10.1038/311024a0. 
Kain, J. S., and J. M. Fritsch, 1998: Multiscale convective overturning in mesoscale convective systems: Reconciling observations, simulations, and theory. Mon. Wea. Rev., 126, 2254-2273, https://doi.org/ 10.1175/1520-0493(1998)126<2254:MCOIMC >2.0.CO;2.

Knoche, H. R., and H. Kunstmann, 2013: Tracking atmospheric water pathways by direct evaporation tagging: A case study for West Africa. J. Geophys. Res. Atmos., 118, 12 345-12358, https://doi.org/10.1002/2013JD019976.

Koster, R., J. Jouzel, R. Suozzo, G. Russell, W. Broecker, D. Rind, and P. Eagleson, 1986: Global sources of local precipitation as determined by the NASA/GISS GCM. Geophys. Res. Lett., 13, 121-124, https://doi.org/10.1029/GL013i002p00121.

Lettau, H., K. Lettau, and L. C. Molion, 1979: Amazonia's hydrologic cycle and the role of atmospheric recycling in assessing deforestation effects. Mon. Wea. Rev., 107, 227-238, https:/doi.org/ 10.1175/1520-0493(1979)107<0227:AHCATR > 2.0.CO;2.

Martinez, J. A., and F. Dominguez, 2014: Sources of atmospheric moisture for the La Plata River basin. J. Climate, 27, 67376753, https://doi.org/10.1175/JCLI-D-14-00022.1.

Merrill, J. T., R. Beck, and D. Boudra, 1986: Techniques of Lagrangian trajectory analysis in isentropic coordinates. Mon. Wea. Rev., 114, 571-581, https://doi.org/10.1175/15200493(1986)114<0571:TOLTAI >2.0.CO;2.

Mesinger, F., and Coauthors, 2006: North American Regional Reanalysis. Bull. Amer. Meteor. Soc., 87, 343-360, https:// doi.org/10.1175/BAMS-87-3-343.

Miguez-Macho, G., A. Rios-Entraza, and F. Dominguez, 2013: The impact of soil moisture and evapotranspiration fluxes on the spring water cycle in the Iberian Peninsula: A study with moisture tracers in WRF. 2013 Fall Meeting, San Francisco, CA, Amer. Geophys. Union, Abstract H12B-05.

Nesbitt, S. W., D. J. Gochis, and T. J. Lang, 2008: The diurnal cycle of clouds and precipitation along the Sierra Madre Occidental observed during NAME-2004: Implications for warm season precipitation estimation in complex terrain. J. Hydrometeor., 9, 728-743, https://doi.org/10.1175/2008JHM939.1.

Numaguti, A., 1999: Origin and recycling processes of precipitating water over the Eurasian continent: Experiments using an atmospheric general circulation model. J. Geophys. Res., 104, 1957-1972, https://doi.org/10.1029/1998JD200026.

Pérez-Muñuzuri, V., J. Eiras-Barca, and D. Garaboa-Paz, 2018: Tagging moisture sources with Lagrangian and inertial tracers: Application to intense atmospheric river events. Earth Syst. Dyn., 9, 785-795, https://doi.org/10.5194/esd-9-785-2018.

Savenije, H. H. G., 1995: New definitions for moisture recycling and the relationship with land-use changes in the Sahel. J. Hydrol., 167, 57-78, https://doi.org/10.1016/0022-1694(94)02632-L.
Schaefli, B., R. J. van der Ent, R. Woods, and H. H. G. Savenije, 2012: An analytical model for soil-atmosphere feedback. Hydrol. Earth Syst. Sci., 16, 1863-1878, https://doi.org/10.5194/ hess-16-1863-2012.

Sodemann, H., C. Schwierz, and H. Wernli, 2008: Interannual variability of Greenland winter precipitation sources: Lagrangian moisture diagnostic and North Atlantic Oscillation influence. J. Geophys. Res., 113, D03107, https://doi.org/ 10.1029/2007JD008503.

- , H. Wernli, and C. Schwierz, 2009: Sources of water vapour contributing to the Elbe flood in August 2002-A tagging study in a mesoscale model. Quart. J. Roy. Meteor. Soc., 135, 205-223, https://doi.org/10.1002/qj.374.

Stohl, A., and P. James, 2004: A Lagrangian analysis of the atmospheric branch of the global water cycle. Part I: Method description, validation, and demonstration for the August 2002 flooding in central Europe. J. Hydrometeor., 5, 656-678, https://doi.org/10.1175/1525-7541(2004)005<0656:ALAOTA > 2.0.CO;2.

van der Ent, R. J., and H. H. G. Savenije, 2011: Length and time scales of atmospheric moisture recycling. Atmos. Chem. Phys., 11, 1853-1863, https://doi.org/10.5194/acp-11-1853-2011.

,,-- B. Schaefli, and S. C. Steele-Dunne, 2010: Origin and fate of atmospheric moisture over continents. Water Resour. Res., 46, W09525, https://doi.org/10.1029/2010WR009127.

- O. O. Tuinenburg, H. R. Knoche, H. Kunstmann, and H. H. G. Savenije, 2013: Should we use a simple or complex model for moisture recycling and atmospheric moisture tracking? Hydrol. Earth Syst. Sci., 17, 4869-4884, https://doi.org/10.5194/ hess-17-4869-2013.

_ L. Wang-Erlandsson, P. W. Keys, and H. H. G. Savenije, 2014: Contrasting roles of interception and transpiration in the hydrological cycle-Part 2: Moisture recycling. Earth Syst. Dyn., 5, 471-489, https://doi.org/10.5194/esd-5-471-2014.

Winschall, A., S. Pfahl, H. Sodemann, and H. Wernli, 2014: Comparison of Eulerian and Lagrangian moisture source diagnostics - The flood event in eastern Europe in May 2010. Atmos. Chem. Phys., 14, 6605-6619, https://doi.org/10.5194/ acp-14-6605-2014.

Yang, Z., F. Dominguez, X. Zeng, H. Hu, H. Gupta, B. Yang, and Z. Yang, 2017: Impact of irrigation over the California Central Valley on regional climate. J. Hydrometeor., 18, 1341-1357, https://doi.org/10.1175/JHM-D-16-0158.1.

Yoshimura, K., T. Oki, N. Ohte, and S. Kanae, 2004: Colored moisture analysis estimates of variations in 1998 Asian monsoon water sources. J. Meteor. Soc. Japan Ser. II, 82 , 1315-1329, https://doi.org/10.2151/jmsj.2004.1315. 